\title{
Introduction: Urban Ecological Restoration
}

\author{
Paul H. Gobster
}

What does ecological restoration mean in an urban context? More than half of the world's population now lives in cities, and in response to the dynamic patterns of urbanization, a growing number of ecologists, land managers, and volunteers are focusing their efforts in and around cities to restore remnants of natural diversity (Ingram 2008). Ecological restoration is still a quite youthful field, yet many scientists and practitioners hold a relatively fixed set of criteria for what defines a successful restoration project, irrespective of where sites are located. Among the criteria commonly stated, sites should be composed of indigenous species, have a structure and diversity characteristic of currently undisturbed or historically documented "reference" sites, and be maintained through ecological processes such as fire that ensure long-term sustainability with minimal human assistance (Ruiz-Jaén and Aide 2005; SER International 2004). Application of these criteria has led to many ecologically successful restorations, but some ecologists in the field have begun to question whether the same standards can be realistically applied to sites such as those within urban areas that have been radically altered by past human activity (e.g., Martínez and López-Barerra 2008) or are being influenced by novel conditions that result in unpredictable trajectories (Choi 2007). Perhaps more significantly, it is becoming increasingly recognized that the broader viability of restoration projects, especially those in urban areas, hinges on how socially successful they are in gaining public acceptance for restoration activities and practices, building constituencies to assist with implementation and maintenance, and addressing a broader set of sustainability goals that reach beyond the protection of native biodiversity (e.g., Choi et al. 2008; Hobbs 2007; Rosenzweig 2003).

For these and other reasons, cities offer a testing ground for how we can expand our thinking about ecological restoration. Doing ecological restoration in urban areas is not a new thing; in fact, in the U.S., some of the earliest experiments in ecological restoration begun by Edith Roberts at Vassar College (1924) and Aldo Leopold at the Uni- 
versity of Wisconsin-Madison (1934) were located in cities (Hall 2005). But these and other early restorations were usually carried out in the context of arboreta and botanic gardens, and it wasn't until the species and management practices prescribed by restorationists jumped the garden wall into the broader urban landscape that the differences between doing ecological restoration in urban areas and doing urban ecological restoration became apparent.

The urban emphasis places people-their values, perceptions, and actions - directly alongside ecological aspects of structure and function as mutually interacting factors in landscape change. This "socialecological system" is just beginning to be understood through the transdisciplinary study of urban ecology, a field even younger than ecological restoration, but one that challenges us to test existing assumptions and entertain new ideas about the interactions between people and their environment (Pickett et al. 2008). Looked at this way, urban ecological restoration offers a unique opportunity to develop ideas, models, and guidelines from research that can foster mutually beneficial human-environment and human-human-environment interactions (Geist and Galatowitsch 1999).

My own research on urban ecological restoration has focused on what nature means to diverse stakeholders groups and how their values and uses are negotiated through the implementation of restoration policies and practices for public parks and natural areas (e.g., Gobster $1997 ; 2001 ; 2007)$. In examining restoration programs in Chicago and San Francisco, I have worked to develop guidelines to make projects more sensitive to social concerns (Hull and Gobster 2001) and proposed a range of alternative models for urban restoration that attempt to address the social and ecological constraints and opportunities of particular sites (Westphal et al. 2010). In presenting a summary of my work at an international conference on forest landscape restoration in Seoul a few years back, I was struck not only by the differences between my "Americentric" experiences and those of other conference participants, but also by commonalities where I least expected them. Feeling both humbled and inspired, I began searching more widely for what restoration means in an urban context, and when invited by the Editors of Nature+Culture to pursue this special symposium, I sought out scholars working in and around this area from a variety of disciplines and geographic locations.

The six papers included in this issue represent disciplinary and professional perspectives in anthropology, geography, political ecology, botany and horticulture, landscape architecture and planning, envi- 
ronmental studies, and philosophy, and feature case studies of restoration in cities on four different continents. As the papers came together they began to offer a richer and more expansive view of the promise and problems that urban ecological restoration entails. While I leave it to the readers to explore each article in its entirety, a few of the insights I have gleaned from the contributions I believe will help strengthen and improve the success of urban restoration efforts:

- The thoughts and feelings that urban dwellers hold about nature in the city are diverse, sometimes contested between stakeholder groups, and may even be ambivalent within individuals. Concepts and practices developed to implement urban ecological restoration thus must be sensitive to multiple understandings (Trigger and Head; Jorgensen and Gobster).

- Expanding constituencies for urban nature requires using restoration opportunities to re-energize traditional working relationships with the land that yield material benefits to people (e.g., food and fiber) while achieving ecological and environmental goals (Terada et al.; Palamar).

- In light of global climate change and other impacts on urban ecosystems, a truly sustainable restoration must look forward and build upon the nature that already exists within cities rather than backward in attempting to recreate from scratch what once existed (Del Tredici).

- In dense urban settings, decisions to favor one type of nature over another can unintentionally lead to favoring certain groups of people and uses and excluding or restricting others. Dedicated efforts toward inclusiveness and participatory engagement in restoration projects are necessary to help minimize disenfranchisement (Palamar; Foster).

- While conserving native diversity is a laudable goal, urban ecological restoration will be more successful if it also addresses a broader range of values, particularly those that serve direct and indirect human desires and needs (all contributors).

These ideas, by turns provocative, encouraging, and challenging, help expand our concept of restoration and what it means in an urban context. While any single compilation such as this cannot provide an exhaustive treatment of urban ecological restoration, the wealth of insights contributed by the authors is testament to its importance as an emerging subfield of inquiry and the value it can bring to broader 
studies of ecological restoration, urban ecology, and other fields that lie at the nexus of nature and culture.

\section{References}

Choi, Young D. 2007. "Restoration Ecology to the Future: A Call for New Paradigm." Restoration Ecology 15 (2): 351-353.

Choi, Young D., Vicky M. Temperton, Edith B. Allen, Albert P. Grootjans, Melinda Halassy, Richard J. Hobbs, M. Anne Naeth, and Katalin Torok. 2008. "Ecological Restoration for Future Sustainability in a Changing Environment." Ecoscience 15 (1): 53-64.

Geist, Cathy, and Susan M. Galatowitsch. 1999. "Reciprocal Model for Meeting Ecological and Human Needs in Restoration Projects." Conservation Biology 13 (5): 970-979.

Gobster, Paul H. 1997. "The Chicago Wilderness and its Critics. III. The Other Side A Survey of the Arguments." Restoration \& Management Notes 15 (1): 32-37.

—. 2001. "Visions of Nature: Conflict and Compatibility in Urban Park Restoration." Landscape and Urban Planning 56 (1): 35-51.

- 2007. "Urban Park Restoration and the Museumification of Nature." Nature and Culture 2 (2): 94-115.

Hall, Marcus. 2005. Earth Repair: A Transatlantic History of Environmental Restoration. Charlottesville: University of Virginia Press.

Hobbs, Richard J. 2007. "Setting Effective and Realistic Restoration Goals: Key Directions for Research." Restoration Ecology 15 (2): 354-357.

Hull, R. Bruce, and Paul H. Gobster. 2000. "Restoring Forest Ecosystems: The Human Dimension." Journal of Forestry 98 (8): 32-36.

Martínez, M. Luisa, and Fabiola López-Barerra. 2008. "Special Issue: Restoring and Designing Ecosystems for a Crowded Planet." Ecoscience 15 (1): 1-5.

Pickett, Steward T. A., Mary L. Cadenasso, J. Morgan Grove, Peter M. Groffman, Lawrence E. Band, Christopher G. Boone, William R. Burch Jr., et al. 2008. "Beyond Urban Legends: An Emerging Framework of Urban Ecology, as Illustrated by the Baltimore Ecosystem Study." BioScience 58 (2): 139-150.

Rosenzweig, Michael L. 2003. Win-Win Ecology: How the Earth's Species Can Survive in the Midst of Human Enterprise. New York: Oxford University Press.

Ruiz-Jaén, Maria C., and T. Mitchell Aide. 2005. "Restoration Success: How is it Being Measured?" Restoration Ecology 13 (3): 569-577.

Society for Ecological Restoration International. 2004. The SER International Primer on Ecological Restoration. Tucson: Society for Ecological Restoration International, Tucson, AZ. http://www.ser.org/pdf/primer3.pdf Accessed 5 May 2010.

Westphal, Lynne M., Paul H. Gobster, and Matthias Gross. 2010. "Models for Renaturing Cities: A Transatlantic view." Pp. 208-217 in Restoration and History: The Search for a Usable Environmental Past, ed. Marcus Hall. New York: Routledge. 